\title{
Evaluation of Symmetric Dimethylarginine and Doppler Ultrasonography in the Diagnosis of Gentamicin-Induced Acute Kidney Injury in Dogs
}

\section{Youssef Mohamed Yassein Elgazzar}

Benha University Faculty of Veterinary Medicine

Mohamed M. Ghanem

Benha University Faculty of Veterinary Medicine

Yassein M. Abdel-Raof

Benha University Faculty of Veterinary Medicine

Mohamed.M.M. Kandiel

Benha University Faculty of Veterinary Medicine

Mahmoud Helal ( $\square$ mahmoud.halal@fvtm.bu.edu.eg)

Benha University Faculty of Veterinary Medicine https://orcid.org/0000-0003-3673-2791

\section{Research Article}

Keywords: Acute kidney injury, dogs, gentamicin, symmetric dimethylarginine, resistive index, Doppler ultrasonography

Posted Date: June 12th, 2021

DOl: https://doi.org/10.21203/rs.3.rs-553617/v1

License: (c) (1) This work is licensed under a Creative Commons Attribution 4.0 International License. Read Full License

Version of Record: A version of this preprint was published at Environmental Science and Pollution Research on September 7th, 2021. See the published version at https://doi.org/10.1007/s11356-02116086-5. 


\section{Abstract}

Acute kidney injury is a common problem in dogs and is associated with significant morbidity and mortality, so this study was aimed to evaluate Symmetric dimethylarginine (SDMA), Doppler ultrasonography including resistive index $(\mathrm{RI})$ in the diagnosis of acute kidney injury in dogs. Ten healthy mongrel dogs were injected with gentamicin sulphate $10 \%$ at the dose of $30 \mathrm{mg} / \mathrm{kg}$ body weight daily for ten days for induction of acute kidney injury. Clinical, Biochemical, Ultrasonographic, Doppler ultrasonographic examinations, and urinalysis were performed for all dogs on zero day before induction, on the $5^{\text {th }}$ day, and the $10^{\text {th }}$ day of induction. The results of the current study showed a significant increase in plasma level of SDMA, serum urea, creatinine, phosphorus, potassium, and a significant decrease in serum sodium, calcium, and chloride on the $5^{\text {th }}$ day and $10^{\text {th }}$ day of induction, there was an increase in renal cortical echogenicity of right and left kidney compared to adjacent liver and spleen, respectively. RI value showed a significant increase on the $5^{\text {th }}$ day and $10^{\text {th }}$ day of induction. This study showed that SDMA is a sensitive, and promising biomarker for diagnosis of acute kidney injury in dogs compared to routine biomarkers also, the RI of Doppler ultrasonography is useful for early identifying acute kidney injury when the only observable change is an increase in cortical echogenicity.

\section{Introduction}

Acute kidney injury is described as a sudden reduction in renal activity leading to uremic waste retention, fluid status modification, electrolyte and acid-base imbalances (Gori et al. 2019). The kidney is sensitive to drug-induced disruption due to comparatively high blood supply (20\% of stroke volume) and the capacity to extract and concentrate toxic molecules (Randjelović et al. 2017). Acute kidney injury has many causes in dogs which can be classified into several main groups, such as renal ischemia (e.g. hypotension), nephrotoxicity (e.g. ethylene glycol, gentamicin), and infectious diseases ( e.g. leptospirosis, pyelonephritis) (Tufani et al. 2017). There is a bad prognosis for acute kidney injury, the mortality rate of acute kidney injury is 50 to $60 \%$ in small animals, with high deaths happened shortly after diagnosis. (Thoen and Kerl 2011).

The slow diagnosis of acute kidney injury due to insensitive diagnostic testing, the subtlety of early symptoms preventing presentation to a veterinarian, and the rapid development of kidney damage associated with nephrotoxins are likely to be important factors in the high mortality rate associated with acute kidney injury (Cobrin et al. 2013). In the early detection of acute kidney injury, conventional blood (creatinine, urea) and urinary markers of kidney damage are insensitive (Han et al. 2008). Acute kidney injury diagnosis is dependent on relative or absolute alteration in serum creatinine concentration and urinary production, but serum creatinine is a late nephropathy biomarker and mild types of kidney injury can go unnoticed (Monari et al. 2020).

Symmetric dimethylarginine (SDMA) is the catabolic product of post-translationally methylated arginine-containing proteins and is excreted mainly by the kidneys(Martens Lobenhoffer and Bode-Böger 2015). SDMA is a new biomarker that accurately reflects the rate of glomerular filtration (GFR) relative to 
serum creatinine, enabling earlier diagnosis of kidney functional dysfunction in dogs, cats, and humans. (Giapitzoglou et al. 2020). For the identification of renal failure, blood SDMA has greater sensitivity With just a 25 to $40 \%$ drop in GFR, SDMA increases while creatinine increases will not be observed until GFR declines by $75 \%$ (Hall et al. 2016). SDMA has the benefit of not being affected by creatinine influencing non-renal causes such as body mass, diet, inflammation, diabetes, and hormone treatment. (Hokamp and Nabity 2016).

The Doppler-based renal resistive index (RI) calculation is one of the most advanced tools for the diagnosis of acute kidney injury. This is a simple and non-invasive investigative technique used in the intensive care unit for the early diagnosis of acute kidney injury (Darmon et al. 2011). For determining conditions that modify renal parenchymal perfusion, pulsed wave Doppler ultrasound is more effective with the benefit that the modifications can be quantified by measuring the resistivity index (RI) and pulsatility index $(\mathrm{PI})$. These indices are determined based on the spectral waveform obtained by pulsed Doppler, using systolic velocity peak values, diastolic velocity end, and mean velocity values (Bragato et al. 2017). The Value of RI is positively correlated with age and not influenced by the sex and weight of dogs (Ostrowska et al. 2016).

This study aims to evaluate the SDMA, and Doppler Ultrasonography including renal RI compared to serum biochemical parameters for the diagnosis of acute kidney injury in dogs and determine the most accurate, and sensitive method for detection of acute kidney injury in the dog.

\section{Material And Methods}

\section{Animal:}

Ten healthy mongrel dogs were used in this study their weight ranged from 10 to $15 \mathrm{Kg}$ and their age ranged from 1 to 3 years. They are healthy based on clinical, biochemical, and ultrasonographic examination. They were housed in separate boxes with plenty of food and water. After two weeks of adaptation, the dogs were injected with $30 \mathrm{mg} / \mathrm{kg}$ of gentamicin sulphate $10 \%$ intramuscular daily for ten days for induction of acute kidney injury(Rivers et al. 1996). Clinical, biochemical, ultrasonographic examinations, Doppler Ultrasonography, and urinalysis were performed for all dogs on zero day before induction, on the $5^{\text {th }}$ day, and on the $10^{\text {th }}$ day of induction.

\section{Samples:}

Two blood samples were collected from each dog from the cephalic vein. The first blood sample was collected in a plain test tube to obtain serum for biochemical analysis. The second blood sample was collected in a lithium heparin tube to obtain plasma for measurement of SDMA.

\section{Biochemical analysis:}


Plasma concentrations of SDMA were analyzed using an automated analyzer (Catalyst One Chemistry Analyzer; IDEXX Laboratories, USA) and the Catalyst SDMA test (IDEXX SDMA test; IDEXX Laboratories). All procedures were performed according to Thanaboonnipat et al. (2020). The predefined reference limit was $<14 \mu \mathrm{g} / \mathrm{dL}$ (Rentko et al. 2013). The urea and creatinine concentration was measured spectrophotometrically using special kits according to the method described by Walker (1990); Peake and Whiting (2006), respectively. Serum chloride, sodium, and potassium levels were determined using a spectrophotometer according to the method described by Dacie and Lewis (1991). Serum calcium and phosphorus were determined by spectrophotometer according to the method described by Cheesbrough (1991).

\section{Urine examination:}

Urine samples were collected by using urethral catheterization according to Kelly (1984), and analysis was made by using urine strips.

\section{Ultrasonographic examination:}

Ultrasonographic examinations were performed without sedation or anesthesia. The dogs were controlled in lateral recumbency i.e., left lateral recumbency for the examination of the right kidney and right lateral recumbency for the examination of the left kidney. The left kidney and right kidney were scanned below the transverse process of first to third lumbar vertebrae for detection of any changes in the tissue architecture of kidneys using Chison E2 portable ultrasound with 5-8 micro convex transducer as described by Penninck and D'Anjou (2015). All examinations were made on zero day before induction, on the $5^{\text {th }}$ day, and $10^{\text {th }}$ day of induction.

\section{Doppler ultrasonographic examination:}

Using Doppler ultrasound (duplex), (Sonoscape E2 portable color doppler, with micro convex 5$8 \mathrm{MHz}$ transducer, China). Renal RI was measured for each kidney. Firstly, the renal interlobar artery was differentiated by color Doppler and then transferred over the chosen artery to the pulsed wave Doppler using a gate of $1.5 \mathrm{~mm}$ width. To prevent the effect of the anesthetics on the renal blood supply, all animals were manually restrained. (Novellas et al. 2007). The image obtained indicated the flow of blood without any aliasing. Multiple pulses were recorded from one artery to three poles for each right and left kidney in each dog. The renal RI from the chosen artery was measured by the ultrasound machine. (Lin and Cher 1997).

\section{Statistical analysis:}

The obtained results from the experiment were expressed as mean \pm SD and were analyzed using one-way ANOVA with repeated measure (SPSS Statistics for Windows, version 25.0. Armonk, NY: IBM Corp). Differences were declared significant when $(P<0.05)$. 


\section{Results}

\section{Clinical findings}

The dogs with induced acute kidney injury showed only signs of depression, dullness appeared on the $5^{\text {th }}$ day of induction, and polyuria, polydipsia, vomiting, dehydration, and tremors appeared on the $10^{\text {th }}$ day of induction.

\section{Urine examination}

Physical examination of urine showed the presence of proteinuria on the $5^{\text {th }}$ day of induction and became more pronounced on the $10^{\text {th }}$ day of induction using strip kits. (Table 1).

\section{Biochemical findings}

Plasma SDMA concentration showed a significant increase on the $5^{\text {th }}$ day of induction $(P<0.05)$. The increase in SDMA was more than 3 folds on the $5^{\text {th }}$ day of induction compared to its level before induction and became highly significant on the $10^{\text {th }}$ day of induction, the increase in SDMA was more than 6 folds on the $10^{\text {th }}$ day of induction compared to its level before induction (Table2). There was a significant increase in serum urea and creatinine level on the $5^{\text {th }}$ day and $10^{\text {th }}$ day of induction. The increase in creatinine level was more than 3 folds on the $5^{\text {th }}$ day of induction compared to its level before induction and increased more than 6 folds on the $10^{\text {th }}$ day of induction compared to its level before induction. The increase in urea level was 5 folds on the $5^{\text {th }}$ day of induction compared to its level on zero day before induction and increased more than 9 folds on the $10^{\text {th }}$ day of induction compared to its level on zero day before induction. Serum level of phosphorus and potassium showed a significant increase in the current study, the increase in serum potassium level was 2 folds on the $5^{\text {th }}$ day of induction compared to its level on zero day before induction and increased 5 folds on the $10^{\text {th }}$ day of induction compared to its level on zero day before induction. The increase in serum phosphorus level was $1 \mathrm{fold}$ on the $5^{\text {th }}$ day of induction compared to its level on zero day before induction and increased 5 folds on the $10^{\text {th }}$ day of induction compared to its level on zero day before induction (Table 2). There was a significant decrease in serum level of calcium, chloride, and sodium on the $5^{\text {th }}$ day of induction and became highly significant on the $10^{\text {th }}$ day of induction (Table 2)

\section{Ultrasonographic findings:}

Ultrasonographic appearance of the kidney before the induction showed that the renal cortex has a homogenous echogenicity. The medulla was uniform in echogenicity and hypoechoic relative to the cortex. The demarcation between the cortex and the medulla was crisp. Ultrasonographic appearance of both kidneys of dogs on zero day before induction revealed that the renal cortical echogenicity of the right kidney was less echogenic than that of the adjacent liver (Fig.1). The renal cortex of the left kidney is less echogenic than the adjacent spleen (Fig.2). 
On the $5^{\text {th }}$ day of induction, the ultrasonographic appearance of the left kidney showed the same echogenicity of the renal cortex when compared with the spleen (Fig.3). The renal cortex of the right kidney showed the same echogenicity when compared with the liver (Fig.4), also renal cortical echogenicity of the right and left kidney became more echogenic compared to their echogenicity on zero day before induction. On the $10^{\text {th }}$ day of induction, the ultrasonographic appearance of the left kidney showed higher echogenicity of the renal cortex when compared with the spleen (Fig.5) and the renal cortex of the right kidney appeared more echogenic than the adjacent liver (Fig. 6), also renal cortical echogenicity of right and left kidney became more echogenic compared to their echogenicity on zero day before induction and the $5^{\text {th }}$ day of induction.

\section{Renal resistive index measurement (Pourcelot index measurement)}

The dogs with induced acute kidney injury showed a significant increase in RI of both kidneys on the $5^{\text {th }}$ day of induction which increased more than 1 fold compared to its value before induction and became highly significant on the $10^{\text {th }}$ day of induction and increased more than 3 folds on $10^{\text {th }}$ day of induction compared to its value before induction (Table.3). (Fig. 7, 8,9).

\section{Discussion}

Acute kidney injury is a term used to characterize an abrupt decline in renal activity, resulting in a loss of urea and creatinine excretion that raises the amount of serum creatinine above the standard reference range (Mugford et al. 2013). Renal dysfunction is among the main causes of canine deaths. It is lifethreatening and often requires urgent diagnosis and treatment. (Athaley et al. 2018).

Acute kidney injury in the current study was induced using $30 \mathrm{mg} / \mathrm{kg}$ of gentamicin sulphate $10 \%$ daily for ten days which is a potent broad-spectrum aminoglycoside that is commonly used especially in the treatment of life-threatening infections caused by Gram-negative and Gram-positive bacilli(Ali 2003). The renal toxicity of gentamicin was associated with its concentration in the renal proximal convoluted tubule, which induced a variety of morphological and biochemical changes in humans and laboratory animals. (Sepehri et al. 2011).

The dogs showed signs of depression, dullness, polyuria, polydipsia, vomiting, dehydration, and tremors due to the harmful effect of gentamicin on renal tissue, and accumulation of nitrogenous wastes, metabolic acidosis, and changes in the gastrointestinal tract (Kumar et al. 2011)and these findings were similar to Helal (2005)and Allaam et al. (2012).

Examination of urine sample revealed that the presence of proteinuria on the $5^{\text {th }}$ day of induction and became more obvious on the $10^{\text {th }}$ day which might be due to decrease glomerular filtration rate which follows the proximal tubular damage caused by a high dose of gentamicin, Glomerular damage increases the permeability of the filtration barrier which increased filtration of protein in urine 
lead to proteinuria(Cianciolo et al. 2016) and these findings were similar to Macanović et al. (2000) ad Helal (2005).

The most promising novel biomarker for early diagnosis of kidney failure that appeared in the last few years is SDMA. SDMA, with asymmetric dimethylarginine and mono methylarginine, is one of the methylated forms resulting from arginine metabolism (Savarese et al. 2018). The findings of 18 human case trials observed a high correlation between SDMA and both GFR and serum creatinine and concluded that SDMA has significant potential as a biomarker of renal function (Kielstein et al. 2006). SDMA has more advantages over serum creatinine in detecting decreased GFR. SDMA detects loss of renal function earlier and is less affected by extrarenal factors such as age, sex, breed, and lean body mass (Kopke et al. 2018).

This study revealed that there was a significant increase in SDMA on the $5^{\text {th }}$ day of induction and $10^{\text {th }}$ day of induction and this indicated that SDMA is a useful novel urinary biomarkers for the detection of acute kidney injury in dogs and these findings were similar to Hall et al. (2016); Relford et al. (2016)and Dahlem et al. (2017).

SDMA is more preferable than creatinine due to serum SDMA concentrations are not affected by lean body mass in dogs or cats, creatinine is an unreliable indicator during acute changes in kidney function due to creatinine concentrations can vary widely with age, gender, muscle mass, muscle metabolism, and its concentration may not change until a significant amount of kidney function has already been lost (Devarajan 2008)and these findings agreeable to Hall et al. (2016)and McKenna et al. (2020).

Concerning to serum level of urea and creatinine, there was a significant increase in serum urea and creatinine level in the present study due to the harmful impact of gentamicin on the kidneys, contributing to renal harm and the failure of the kidneys to eliminate waste products through reducing the rate of glomerular filtration (Sun et al. 2019), and these findings were agreeable with Helal (2005); Allaam et al. (2012)and Udupa and Prakash (2019).

There was a significant increase in serum potassium and phosphorus on the $5^{\text {th }}$ day of induction and became highly significant on the $10^{\text {th }}$ day of induction and this occurs due to acute renal insufficiency lead to reduced GFR with low urine flow lead to decrease renal excretion of potassium and subsequent hyperkalemia (Lehnhardt and Kemper 2011) and also significant hyperkalemia and hyperphosphatemia may occur due to leakage of potassium and phosphate from the intracellular fluids to the extracellular fluids (Haycock 2003; Ramesh and Reeves 2003) and these findings were coincided with Vaden et al. (1997)and Helal (2005).

Regarding to serum level of calcium, chloride, and sodium, the significant decrease in serum sodium, chloride, and calcium appeared on the $5^{\text {th }}$ day of induction and became highly significant on the $10^{\text {th }}$ day of induction might be attributed to the adverse effect of gentamicin on renal tubules, in particular 
proximal convoluted tubules, and kidney failure to maintain the balance of electrolytes (Stephen et al.2017) and these findings were similar to Helal (2005)and Christo et al. (2011).

The kidney diseases diagnosed by ultrasonography can be classified into diffuse renal diseases, regional renal diseases, and focal or multifocal renal diseases. The diffuse renal diseases diagnosed were nephritis and end-stage kidney (Dehmiwal et al. 2016).

The results of the ultrasonographic examination in the present study revealed that increase renal cortical echogenicity of right and left kidney on the $5^{\text {th }}$ day of induction of acute kidney injury and had the same echogenicity of adjacent liver and spleen, respectively, and became more echogenic than adjacent liver and spleen, respectively on $10^{\text {th }}$ day of induction and this due to extensive accumulation of gentamicin in kidney and increase amount of gentamicin bound to the renal cortex (Wiland and Szechiński 2003) and these findings were similar to Rivers et al. (1996); Helal(2005); Allaam et al. (2012)and Sonet et al. (2018).

Alterations in the RI have been observed in many conditions affecting the kidney, such as acute variations in renal vascular resistance and renal damage in multiple organ dysfunction syndromes (Agut et al. 2020). For the evaluation of renal hemodynamics, Doppler ultrasonography can be used and becomes very helpful in the diagnosis of the renal artery and vein diseases such as thrombosis (Donia et al. 2019). The renal resistive index is probably the most commonly used parameter to evaluate blood flow in kidney vessels (Samoni et al. 2016). The resistive index (RI) measures the arterial resistance in the peripheral vessels by calculating the ratio between the peak systolic velocity (PSV) and the end diastolic velocity $(E D V)(R I=(P S V-E D V) / P S V)$, which is independent of the angle and the position of the transducer, allowing accurate and reproducible measurements (Tipisca et al. 2016).

The Renal RI was significantly increased in the present study on the $5^{\text {th }}$ day of induction and became highly significant on the $10^{\text {th }}$ day of induction due to vasoconstriction resulting from renin release in response to the decreased blood flow in the renal arteries secondary to renal injury(Chang et al. 2010). These results coincided with Morrow et al. (1996); Novellas et al. (2007) and Donia et al. (2019). Therefore, the RI is useful for the diagnosis of acute kidney injury when the only observable change is an increase in renal cortical echogenicity and also when there is no alteration in B-mode ultrasound examination(Rivers et al. 1997).

\section{Conclusions}

The results of the present study indicated that the RI is useful for identifying acute kidney injury when the only observable change is an increase in cortical echogenicity. SDMA is a sensitive, specific, and promising biomarker for the diagnosis of acute kidney injury in dogs. Further studies are required for using SDMA in the early diagnosis of renal diseases in small animals.

\section{Declarations}


Acknowledgment:

Not applicable

\section{Availability of data and materials}

The datasets used and/or analyzed during the current study are available from the corresponding author on reasonable request.

\section{Authors' contributions}

YMYE and MAYH conducting experiment and manuscript writing; MMG, YMA, , MAYH, experiment conception, academic supervision and results revision; MMMK, Doppler ultrasonography, ; YMYE, MMG, YMA, and MAYH analysis procedures and results; YMYE, MMG, YMA and MAYH edit the manuscript. All authors read and approved the manuscript.

\section{Conflict of interest}

The authors declare that they have no conflict of interest

\section{Ethical approval}

All examinations were done after approval of the Ethics committee of Benha University with approval number (BUFVTM04032020).

\section{Consent to participate}

Not applicable

\section{Consent for publication}

Not applicable

\section{Funding}

Not applicable

\section{References}

1. Agut A, Soler M, Josefa Fernández-Del Palacio $M(2020)$ Changes in renal resistive index values in healthy puppies during the first months of life. Animals 10:1-7. https://doi.org/10.3390/ani10081338

2. Ali BH (2003) Agents ameliorating or augmenting experimental gentamicin nephrotoxicity: Some recent research. Food Chem Toxicol 41:1447-1452. https://doi.org/10.1016/S0278-6915(03)00186- 
3. Allaam, M., Nayel, M., Elsafy, A. and Hassan, H., (2012) Ultrasonographic and biochemical Diagnosis of Experimental nephrotoxicity in Dogs. $7^{\text {th }}$ scientific conference 24-27 April 2012, 426-440.

4. Athaley A, Bhojne GR, Khanolkar VM, et al (2018) Urine Analysis and Ultrasonographic Findings of Dogs Suffering from Renal Failure. Int J Curr Microbiol Appl Sci 7:1971-1977. https://doi.org/10.20546/ijcmas.2018.710.227

5. Bragato N, Borges NC, Fioravanti MCS (2017) B-mode and Doppler ultrasound of chronic kidney disease in dogs and cats. Vet Res Commun 41:307-315. https://doi.org/10.1007/s11259-017-96949

6. Chang YJ, Chan IP, Cheng FP, et al (2010) Relationship between age, plasma renin activity, and renal resistive index in dogs. Vet Radiol Ultrasound 51:335-337.

7. Cheesbrough M (1991) Medical laboratory Manual for Tropical countries 2nd edition. Top Heal Technol Butterworth Sci limited(1) 494-529.

8. Christo JS, Rodrigues AM, Mouro MG, et al (2011) Nitric oxide (NO) is associated with gentamicin (GENTA) nephrotoxicity and the renal function recovery after suspension of GENTA treatment in rats. Nitric Oxide 24:77-83.

9. Cianciolo R, Hokamp J, Nabity M (2016) Advances in the evaluation of canine renal disease. Vet J 215:21-29. https://doi.org/10.1016/j.tvjl.2016.04.012

10. Cobrin AR, Blois SL, Kruth SA, et al (2013) Biomarkers in the assessment of acute and chronic kidney diseases in the dog and cat. J Small Anim Pract 54:647-655. https://doi.org/10.1111/jsap.12150

11. Dacie J V, Lewis SM (1991) Practical Textbook of Haematology 7th Edition Edinburgh. Church Livingstone 7:54-79.

12. Dahlem DP, Neiger R, Schweighauser A, et al (2017) Plasma Symmetric Dimethylarginine Concentration in Dogs with Acute Kidney Injury and Chronic Kidney Disease. J Vet Intern Med 31:799-804. https://doi.org/10.1111/jvim.14694

13. Darmon M, Schortgen F, Vargas F, et al (2011) Diagnostic accuracy of Doppler renal resistive index for reversibility of acute kidney injury in critically ill patients. Intensive Care Med 37:68-76. https://doi.org/10.1007/s00134-010-2050-

14. Dehmiwal D, Behl SM, Singh P, et al (2016) Diagnosis of pathological conditions of kidney by twodimensional and three-dimensional ultrasonographic imaging in dogs. Vet World 9:693-698. https://doi.org/10.14202/vetworld.2016.693-698

15. Devarajan P (2008) Neutrophil gelatinase-associated lipocalin (NGAL): A new marker of kidney disease. Scand J Clin Lab Invest 68:89-94. https://doi.org/10.1080/00365510802150158

16. Donia MA, Abdelmegeid M, Nassif MN (2019) Biomarkers versus duplex ultrasonography for early detection of acute kidney injury in dogs: an experimental study. Slovenian Veterinary Research, 56(Suppl. 22), pp.179-186 https://doi.org/10.26873/SVR-755-2019

17. Giapitzoglou S, Saridomichelakis MN, Leontides LS, et al (2020) Evaluation of serum symmetric dimethylarginine as a biomarker of kidney disease in canine leishmaniosis due to Leishmania 
infantum. Vet Parasitol 277:109015. https://doi.org/10.1016/j.vetpar.2019.109015

18. Gori E, Lippi I, Guidi G, et al (2019) Acute pancreatitis and acute kidney injury in dogs. Vet J 245:7781. https://doi.org/10.1016/j.tvjl.2019.01.002

19. Hall JA, Yerramilli M, Obare E, et al (2016) Serum Concentrations of Symmetric Dimethylarginine and Creatinine in Dogs with Naturally Occurring Chronic Kidney Disease. J Vet Intern Med 30:794-802. https://doi.org/10.1111/jvim.13942

20. Han WK, Waikar SS, Johnson A, et al (2008) Urinary biomarkers in the early diagnosis of acute kidney injury. Kidney Int 73:863-869. https://doi.org/10.1038/sj.ki.5002715

21. Haycock GB (2003) Management of acute and chronic renal failure in the newborn. Semin Neonatol 8:325-334. https://doi.org/10.1016/S1084-2756(03)00044-7

22. Helal MAY (2005) Diagnosis of experimentally-induced kidney affections in dogs using ultrasonography and other methods. M.V.Sc.Thesis,2005.Fac. Vet. Med. Benha.Univ.

23. Hokamp JA, Nabity MB (2016) Renal biomarkers in domestic species. Vet Clin Pathol 45:28-56.

24. Kelly, W.R., (1984) Veterinary clinical diagnosis (No. Edition 3). Bailliere Tindall.

25. Kielstein JT, Salpeter SR, Bode-Boeger SM, et al (2006) Symmetric dimethylarginine (SDMA) as endogenous marker of renal function - A meta-analysis. Nephrol Dial Transplant 21:2446-2451. https://doi.org/10.1093/ndt/gfl292

26. Kopke MA, Burchell RK, Ruaux CG, et al (2018) Variability of Symmetric Dimethylarginine in Apparently Healthy Dogs. J Vet Intern Med 32:736-742. https://doi.org/10.1111/jvim.15050

27. Kumar V, Kumar A, Varshney AC (2011) Ultrasonographic Imaging for Structural Characterization of Renal Affections and Diagnosis of Associated Chronic Renal Failure in 10 Dogs. ISRN Vet Sci 2011:1-11. https://doi.org/10.5402/2011/901713

28. Lehnhardt A, Kemper MJ (2011) Pathogenesis, diagnosis and management of hyperkalemia. Pediatr Nephrol 26:377-384. https://doi.org/10.1007/s00467-010-1699-3

29. Lin GJ, Cher TW (1997) Renal vascular resistance in normal children - A color Doppler study. Pediatr Nephrol 11:182-185. https://doi.org/10.1007/s004670050255

30. Macanović M, Lazarević M, Janković-Zagorčić A, Đurđević D (2000) Serum and urine laboratory analyses in dogs with gentamicin induced acute renal failure. Acta Vet 50:83-92.

31. Martens-Lobenhoffer J, Bode-Böger SM (2015) Amino acid N-acetylation: Metabolic elimination of symmetric dimethylarginine as symmetric $\mathrm{Na}$-acetyldimethylarginine, determined in human plasma and urine by LC-MS/MS. J Chromatogr B 975:59-64.

32. McKenna M, Pelligand L, Elliott J, et al (2020) Relationship between serum iohexol clearance, serum SDMA concentration, and serum creatinine concentration in non-azotemic dogs. J Vet Intern Med 34:186-194. https://doi.org/10.1111/jvim.15659

33. Monari E, Troìa R, Magna L, et al (2020) Urine neutrophil gelatinase-associated lipocalin to diagnose and characterize acute kidney injury in dogs. J Vet Intern Med 34:176-185. 
34. Morrow KL, Salman MD, Lappin MR, Wrigley R (1996) Comparison of the resistive index to clinical parameters in dogs with renal disease. Vet Radiol Ultrasound 37:193-199.

35. Mugford A, Li R, Humm K (2013) Acute kidney injury in dogs and cats 1. Pathogenesis and diagnosis. In Pract 35:253-264. https://doi.org/10.1136/inp.f2868

36. Novellas R, Espada Y, De Gopegui RR (2007) Doppler ultrasonographic estimation of renal and ocular resistive and pulsatility indices in normal dogs and cats. Vet Radiol Ultrasound 48:69-73. https://doi.org/10.1111/j.1740-8261.2007.00206.x

37. Ostrowska J, Kiełbowicz Z, Zaleska-Dorobisz U, et al (2016) Resistive index (RI) obtained in renal interlobar arteries of normal dogs and cats by means of Doppler ultrasonography. Pak Vet J 36:4548.

38. Peake M, Whiting M (2006) Measurement of serum creatinine-current status and future goals. Clin Biochem Rev 27:173.

39. Penninck, D. and d'Anjou, M.A. (2015) Kidneys and ureters. Atlas Small Animal Ultrasound, Second Ed. Ames: Wiley Blackwell, pp.331-61.

40. Ramesh G, Reeves WB (2003) TNFR2-mediated apoptosis and necrosis in cisplatin-induced acute renal failure. Am J Physiol - Ren Physiol 285:610-618. https://doi.org/10.1152/ajprenal.00101.2003

41. Randjelović P, Veljković S, Stojiljković N, et al (2017) Gentamicin nephrotoxicity in animals: Current knowledge and future perspectives. EXCLI J 16:388-399. https://doi.org/10.17179/excli2017-165

42. Relford R, Robertson J, Clements C (2016) Symmetric Dimethylarginine: Improving the Diagnosis and Staging of Chronic Kidney Disease in Small Animals. Vet Clin North Am - Small Anim Pract 46:941960. https://doi.org/10.1016/j.cvsm.2016.06.010

43. Rentko V, Nabity M, Yerramilli M, et al (2013) P-7 Determination of serum symmetric dimethyllarginine reference limit in clinically healthy dogs. J Vet Intern Med 27:3.

44. Rivers BJ, Walter PA, Holm JC, et al (1996) Gray-scale sonographic characterization of aminoglycoside-induced nephrotoxicosis in a canine model. Invest Radiol 31:639-651.

45. Rivers BJ, Walter PA, Polzin DJ, King VL (1997) Duplex Doppler estimation of intrarenal Pourcelot resistive index in dogs and cats with renal disease. J Vet Intern Med 11:250-260.

46. Samoni S, Nalesso F, Meola M, et al (2016) Intra-parenchymal renal resistive index variation (IRRIV) describes renal functional reserve (RFR): pilot study in healthy volunteers. Front Physiol 7:286.

47. Savarese A, Probo M, Locatelli C, et al (2018) Reliability of symmetric dimethylarginine in dogs with myxomatous mitral valve disease as kidney biomarker. Open Vet J 8:318. https://doi.org/10.4314/ovj.v8i3.11

48. Sepehri G, Derakhshanfar A, Zadeh FY (2011) Protective effects of corn silk extract administration on gentamicin-induced nephrotoxicity in rat. Comp Clin Path 20:89-94.

49. Sonet J, Barthélemy A, Goy-Thollot I, Pouzot-Nevoret C (2018) Prospective evaluation of abdominal ultrasonographic findings in 35 dogs with leptospirosis. Vet Radiol Ultrasound 59:98-106. https://doi.org/10.1111/vru.12571 
50. Stephen J. Ettinger, Edward C. Feldman EC (2017) Textbook of Veterinary Internal Medicine: Diseases of the dog and the cat, Eighth Edition

51. Sun B, Zhou X, Qu Z, et al (2019) Urinary biomarker evaluation for early detection of gentamycininduced acute kidney injury. Toxicol Lett 300:73-80. https://doi.org/10.1016/j.toxlet.2018.10.027

52. Thanaboonnipat C, Sutayatram S, Buranakarl C, Choisunirachon N (2020) Renal ultrasonographic strain elastography and symmetric dimethylarginine (SDMA) in canine and feline chronic kidney disease. J Vet Med Sci 19-496.

53. Thoen ME, Kerl ME (2011) Characterization of acute kidney injury in hospitalized dogs and evaluation of a veterinary acute kidney injury staging system. J Vet Emerg Crit Care 21:648-657. https://doi.org/10.1111/j.1476-4431.2011.00689.x

54. Tipisca V, Murino C, Cortese $L$, et al (2016) Resistive index for kidney evaluation in normal and diseased cats. J feline Med surgery, 18(6), pp471-475. https://doi.org/10.1177/1098612X15587573

55. Tufani NA, Singh JL, Kumar M, et al (2017) Differential diagnosis of acute versus chronic renal failure in canines with special reference to clinical manifestations. Med Sci 21:66-74.

56. Udupa V, Prakash V (2019) Gentamicin induced acute renal damage and its evaluation using urinary biomarkers in rats. Toxicol Reports 6:91-99. https://doi.org/10.1016/j.toxrep.2018.11.015

57. Vaden SL, Levine J, Breitschwerdt EB (1997) A retrospective case-control of acute renal failure in 99 dogs. J Vet Intern Med 11:58-64. https://doi.org/10.1111/j.1939-1676.1997.tb00074.x

58. Walker HK (1990) The origins of the history and physical examination. In: Clinical Methods: The History, Physical, and Laboratory Examinations. 3rd edition. Butterworths

59. Wiland P, Szechiński J (2003) Proximal tubule damage in patients treated with gentamicin or amikacin. Pol J Pharmacol 55:631-637.

\section{Tables}

Table 1: Urinalysis of dogs with acute kidney injury on zero day before induction, on $5^{\text {th }}$ day and $10^{\text {th }}$ day of induction

\begin{tabular}{|llll|}
\hline & Zero day Before induction & $5^{\text {th }}$ day of induction & $10^{\text {th }}$ day of induction \\
\hline $\mathrm{pH}$ & 6 & 6 & 7 \\
\hline Protein & - & ++ & +++ \\
\hline Bilirubin & - & - & - \\
\hline Ketone & - & - & - \\
\hline Glucose & - & - & - \\
\hline Blood & - & - & - \\
\hline Nitrite & - & - & - \\
\hline
\end{tabular}


Table 2: Serum biochemical parameters on zero day before induction, on $5^{\text {th }}$ day and $10^{\text {th }}$ day of induction in dogs with acute kidney injury

\begin{tabular}{|c|c|c|c|}
\hline & Zero day Before induction & $5^{\text {th }}$ day of induction & $10^{\text {th }}$ day of induction \\
\hline SDMA (ug/dl) & $13 \pm 0.94^{c}$ & $37.3 \pm 14^{\mathrm{b}}$ & $70.8 \pm 1.86^{a}$ \\
\hline Urea(mg/dl) & $31.4 \pm 5.76^{c}$ & $82.011 \pm 10.89^{b}$ & $125.04 \pm 5.13^{a}$ \\
\hline Creatinine(mg/dl) & $0.644 \pm 0.132^{c}$ & $2.692 \pm 0.48^{b}$ & $6.197 \pm 0.62^{\mathrm{a}}$ \\
\hline Sodium (mEq/l) & $143.76 \pm 4.26^{a}$ & $102.797 \pm 13.84^{b}$ & $77.177 \pm 4.51^{\mathrm{c}}$ \\
\hline Potassium (mEq/l) & $5.008 \pm 0.68^{c}$ & $7.592 \pm 1.19^{b}$ & $10.881 \pm 0.97^{a}$ \\
\hline $\begin{array}{l}\text { Phosphorus } \\
\text { (mg/dl) }\end{array}$ & $5.516 \pm 0.53^{c}$ & $6.123 \pm 0.66^{b}$ & $11.018 \pm 0.83^{a}$ \\
\hline Chloride (mg/dl) & $102.231 \pm 2.46^{a}$ & $79.339 \pm 6.85^{b}$ & $51.237 \pm 6.9^{c}$ \\
\hline Calcium (mg/dl) & $9.881 \pm 0.44^{\mathrm{a}}$ & $7.622 \pm 0.29^{b}$ & $4.992 \pm 0.5^{\mathrm{c}}$ \\
\hline
\end{tabular}

Data are presented as (Mean \pm SD). S.D = Standard deviation. Mean values with different superscript letters in the same column are significantly different at $(P<0.05)$

Table 3; Value of RI on zero day before induction, on $5^{\text {th }}$ day and $10^{\text {th }}$ day of induction in dogs with acute kidney injury

\begin{tabular}{|llll|}
\hline & zero day before induction & $\boldsymbol{5}^{\text {th }}$ day of induction & $\mathbf{1 0}^{\text {th }}$ day of induction \\
\hline $\mathrm{Rl}$ & $0.507 \pm 0.04^{\mathrm{c}}$ & $0.647 \pm 0.02^{\mathrm{b}}$ & $0.865 \pm 0.07^{\mathrm{a}}$ \\
\hline
\end{tabular}

Data are presented as (Mean \pm SD). S.D = Standard deviation. Mean values with different superscript letters in the same column are significantly different at $(P<0.05)$

\section{Figures}




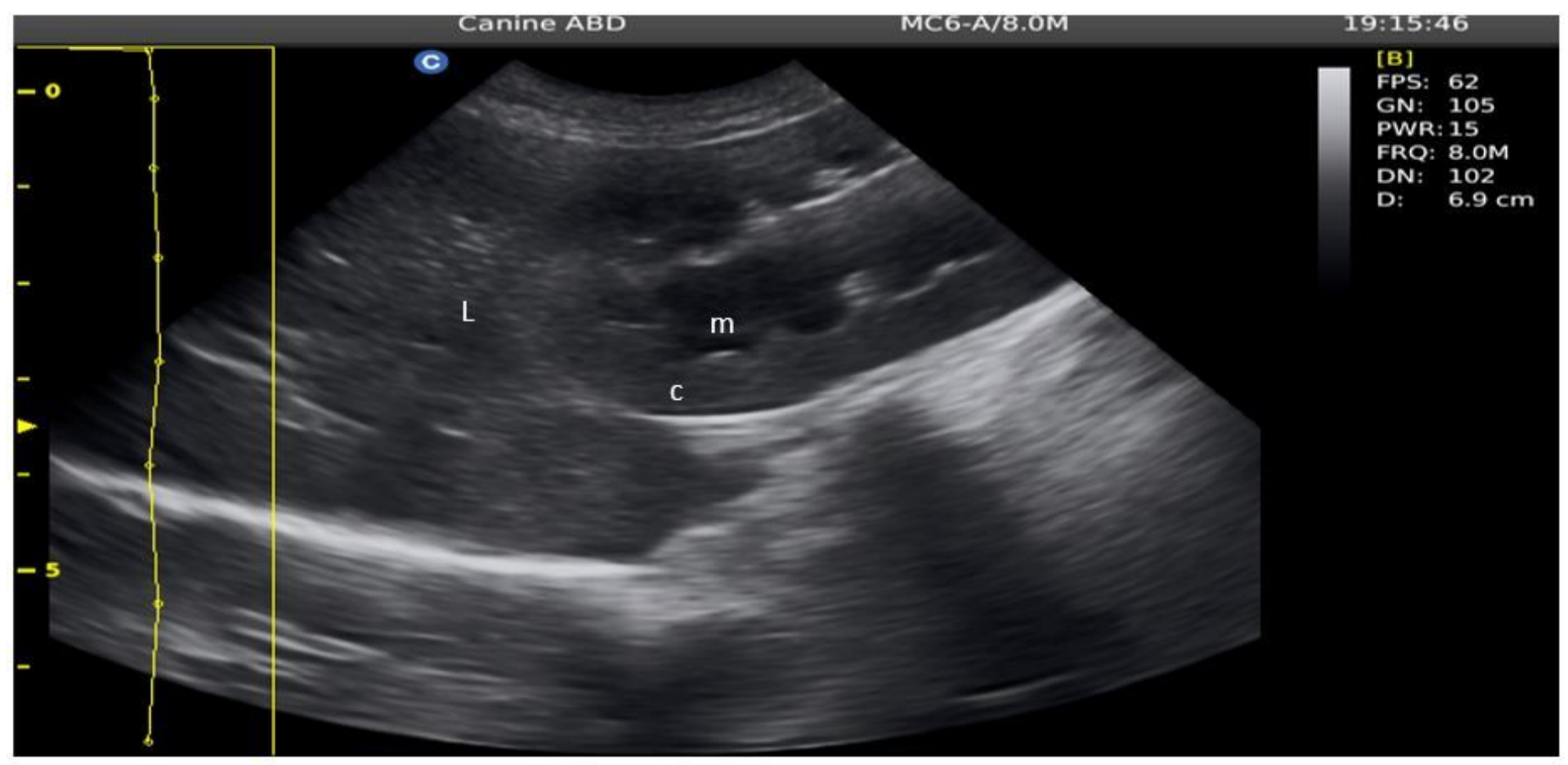

\section{Figure 1}

Ultrasonographic examination of the Right kidney of dogs on zero day before induction of acute kidney injury showed that renal cortical echogenicity of $\operatorname{cortex}(\mathrm{C})$ less echogenic than adjacent liver ( $\mathrm{L}$ )

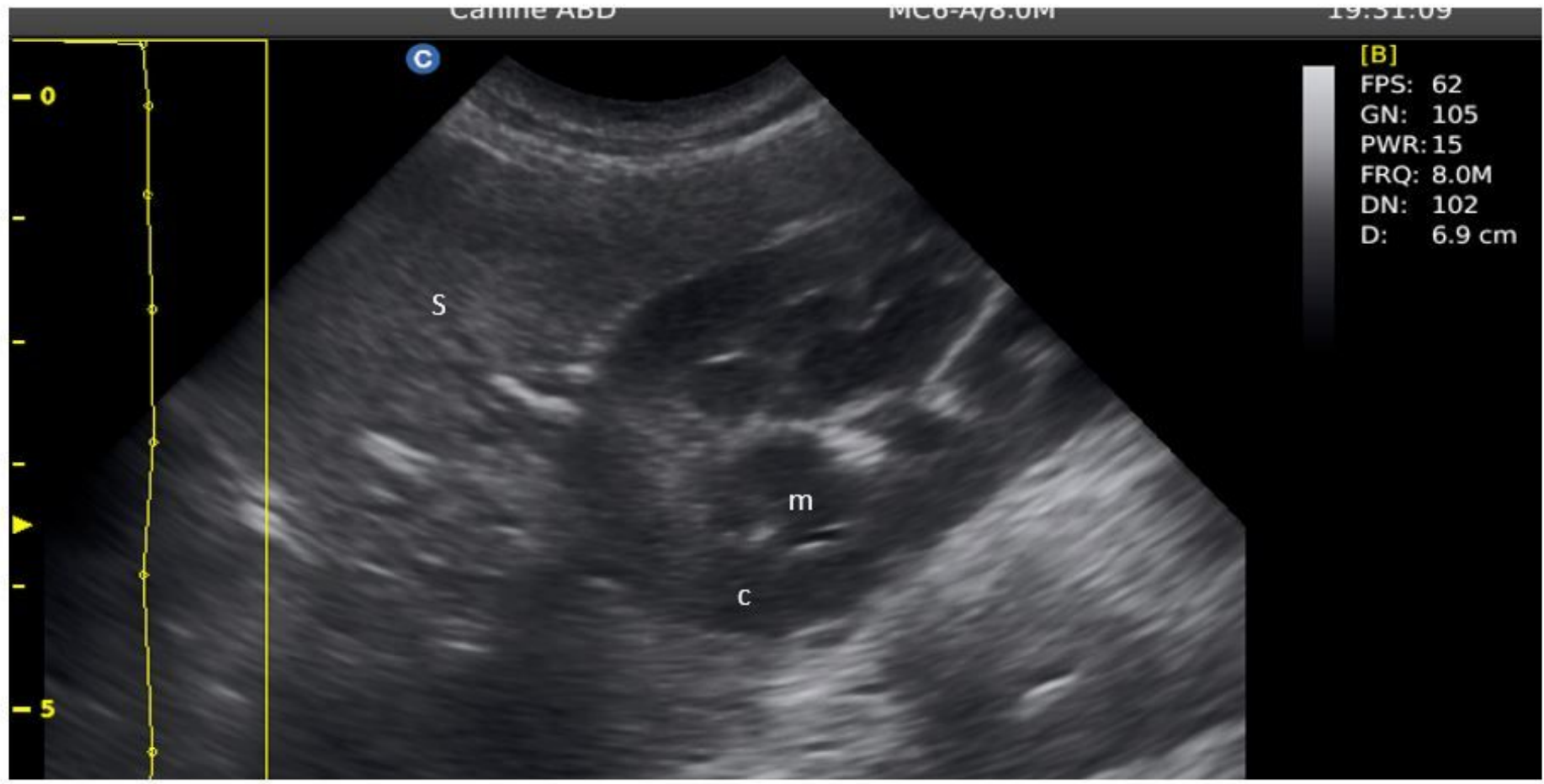

\section{Figure 2}

Ultrasonographic examination of the left kidney of dogs on zero day before induction of acute kidney injury showed that renal cortical echogenicity (C ) less echogenic than adjacent spleen ( S ) 


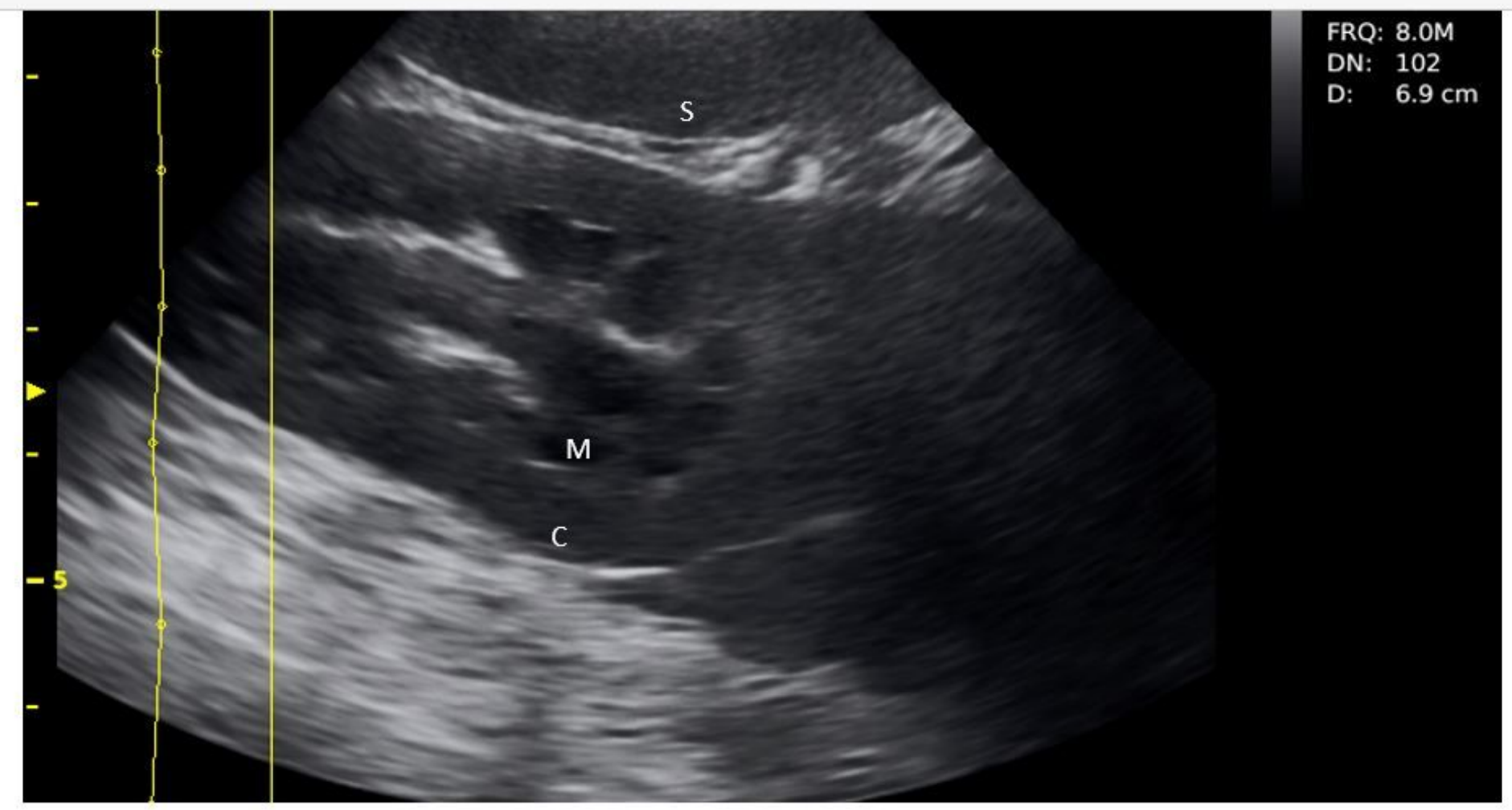

\section{Figure 3}

Ultrasonographic examination of the Left kidney of dogs on 5th day of induction showed that renal cortical echogenicity of cortex ( C ) has the same echogenicity of adjacent spleen ( S )

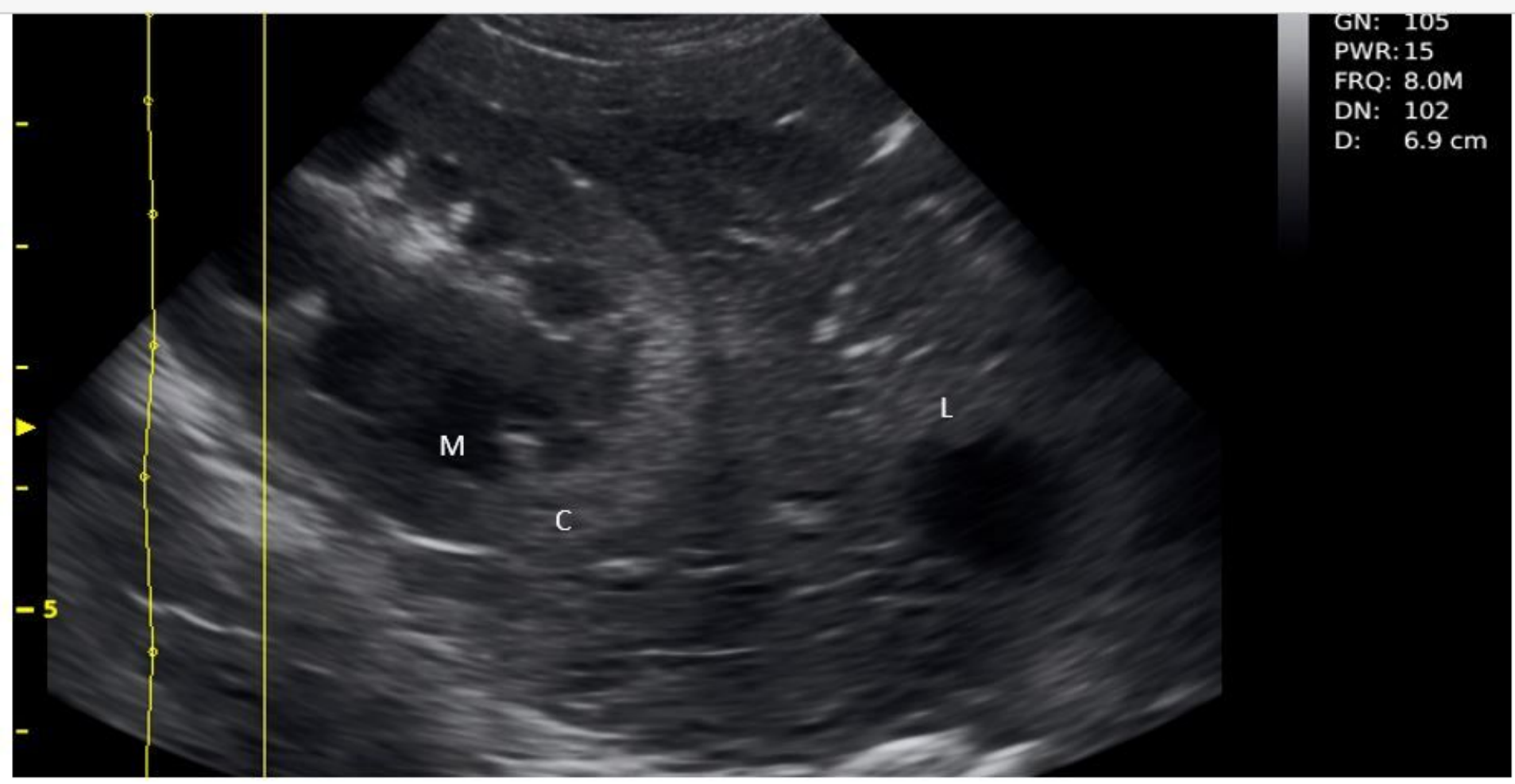

Figure 4 
Ultrasonographic examination of the Right kidney of dogs on 5th day of induction showed that renal cortical echogenicity of cortex ( C ) has the same echogenicity of adjacent liver ( $L$ ).

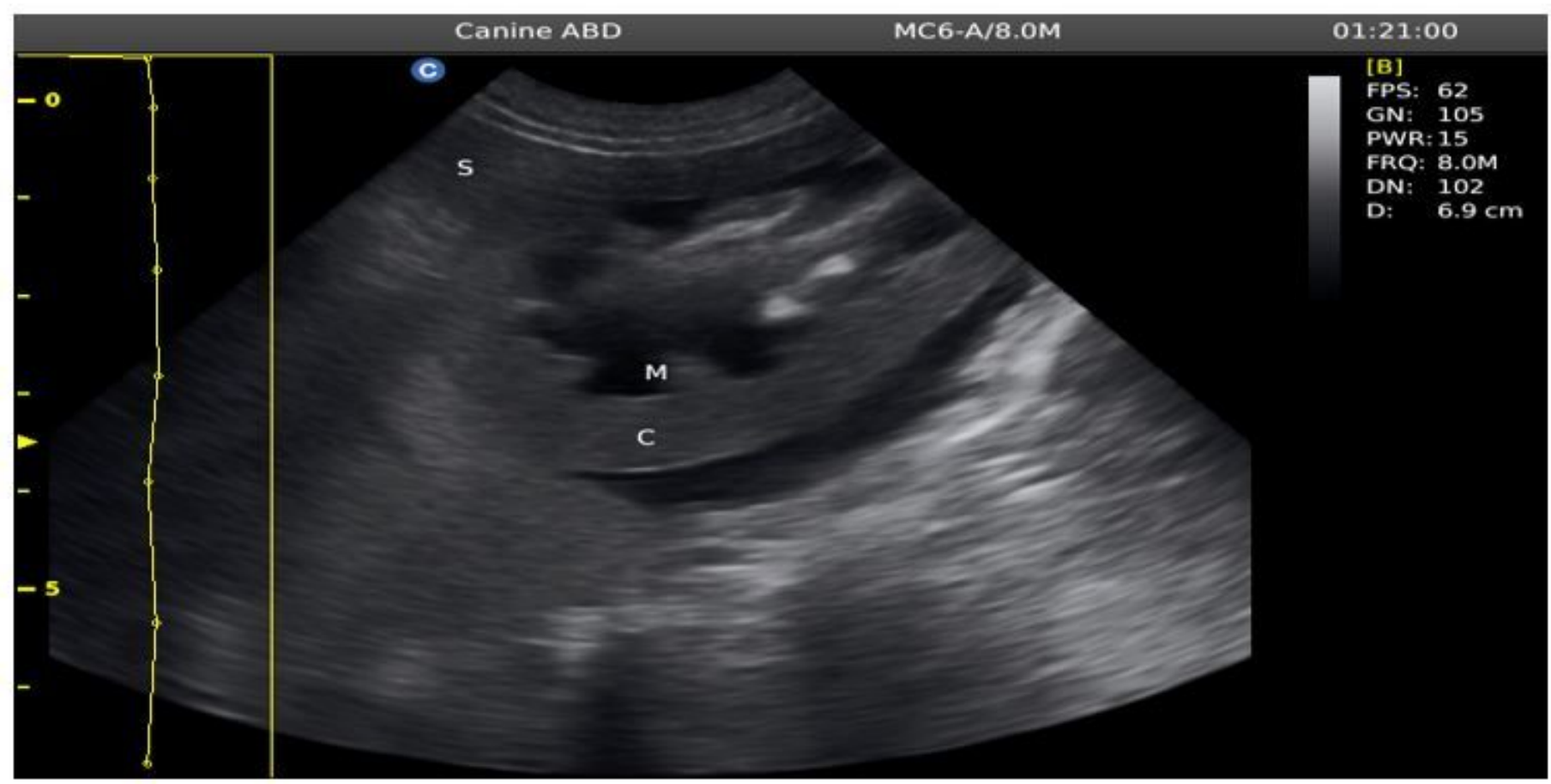

\section{Figure 5}

Ultrasonographic examination of Left kidney of dogs at 10th day of induction showed that renal cortical echogenicity ( C ) more echogenic than adjacent spleen ( S )

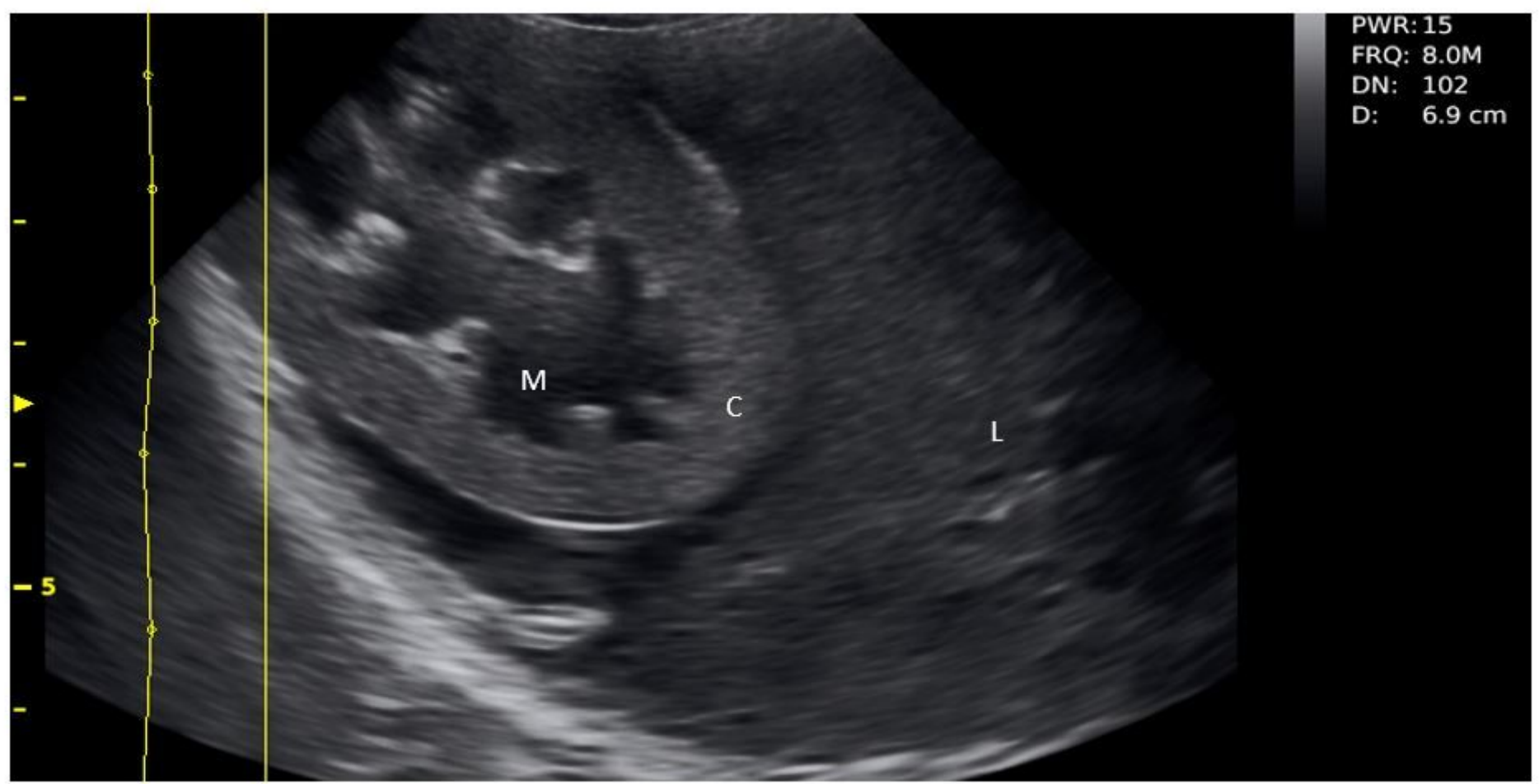

\section{Figure 6}


Ultrasonographic examination of the Right kidney of dogs on 10th day of induction showed that renal cortical echogenicity ( C ) more echogenic than adjacent liver ( $\mathrm{L}$ )

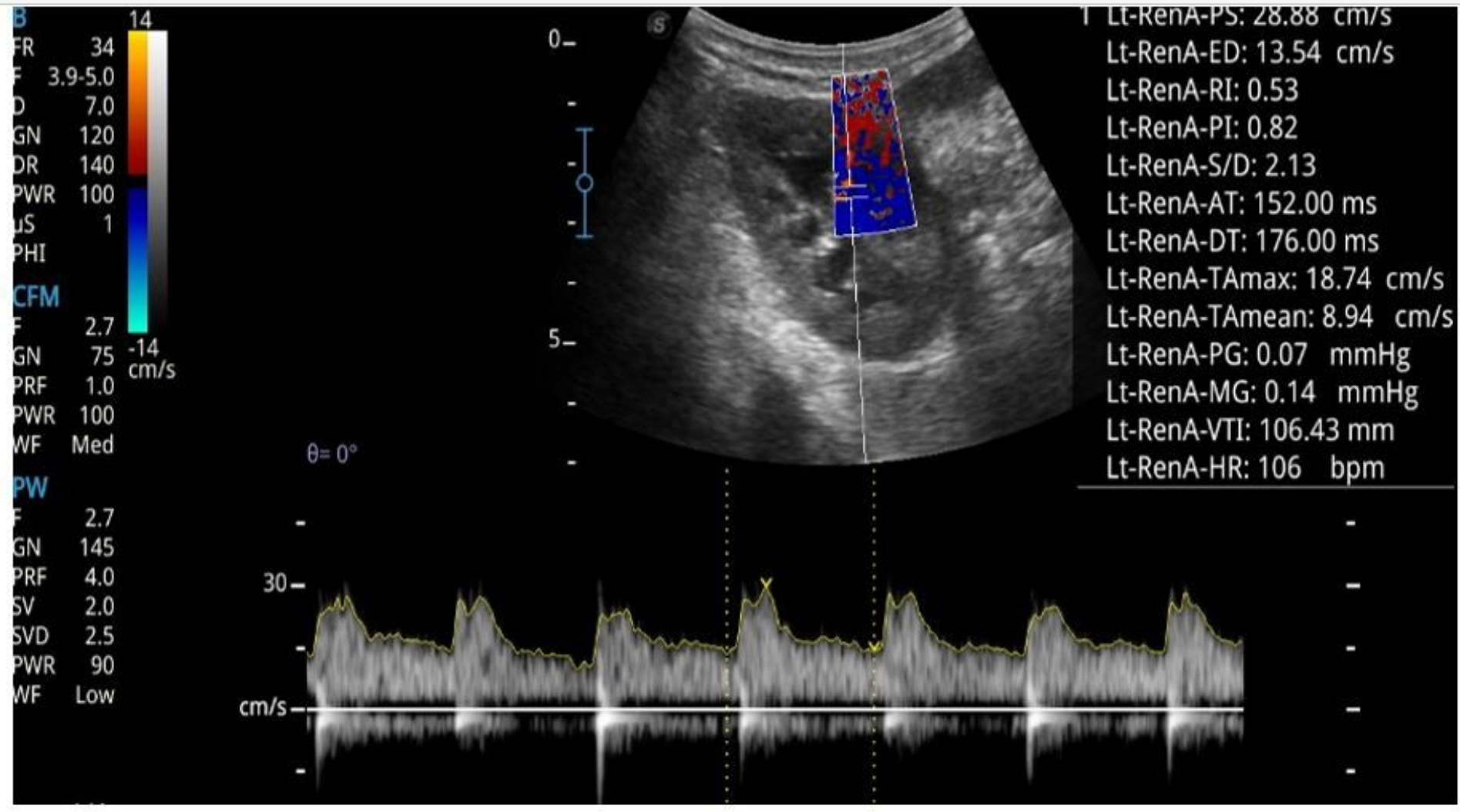

\section{Figure 7}

Pulsed wave Doppler ultrasonographic image of the interlobar artery on zero day before induction of acute kidney injury showing RI value equal 0.53

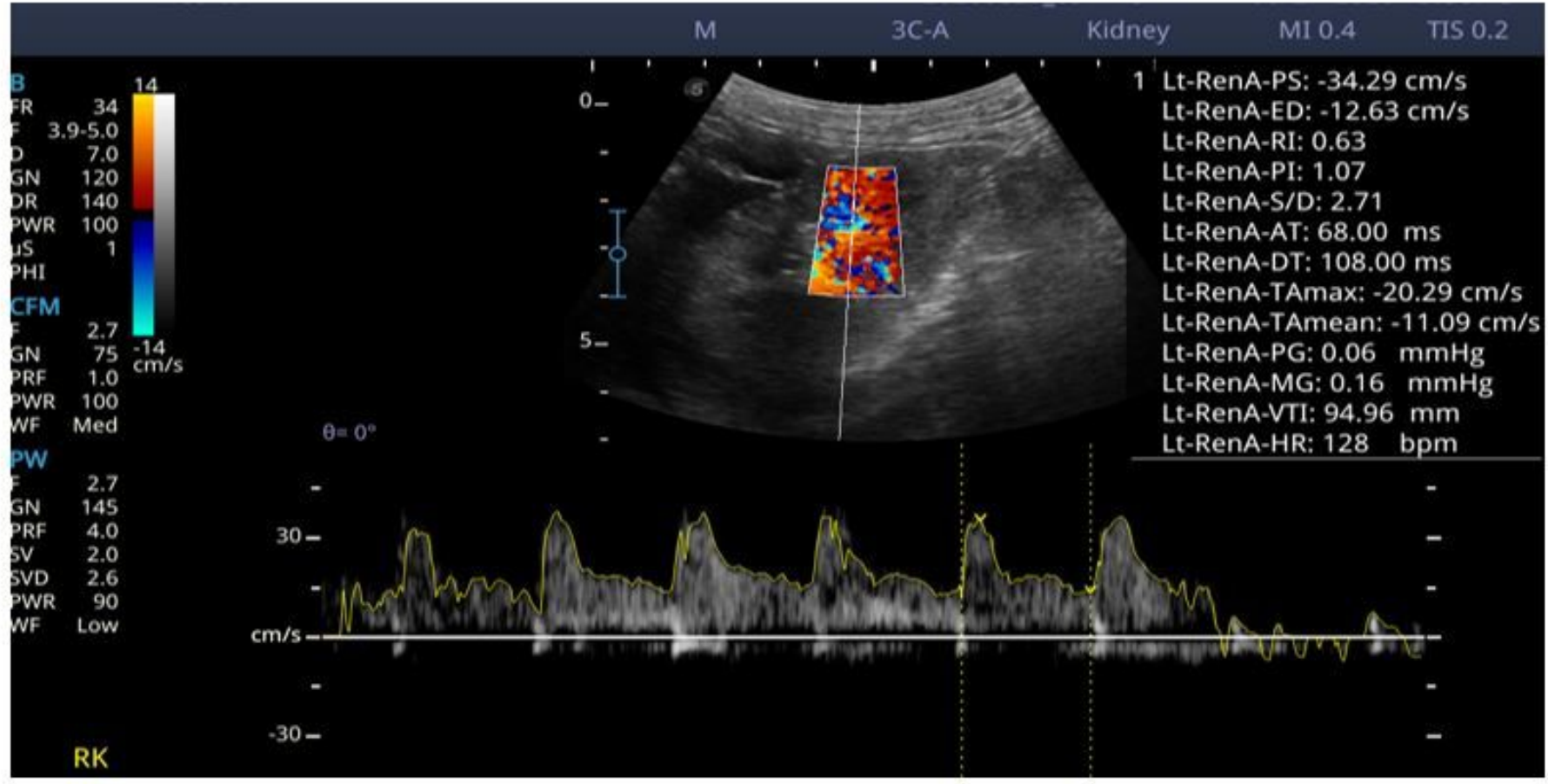




\section{Figure 8}

Pulsed wave Doppler ultrasonographic image of the interlobar artery on 5th day before induction of acute kidney injury showing RI value equal 0.63

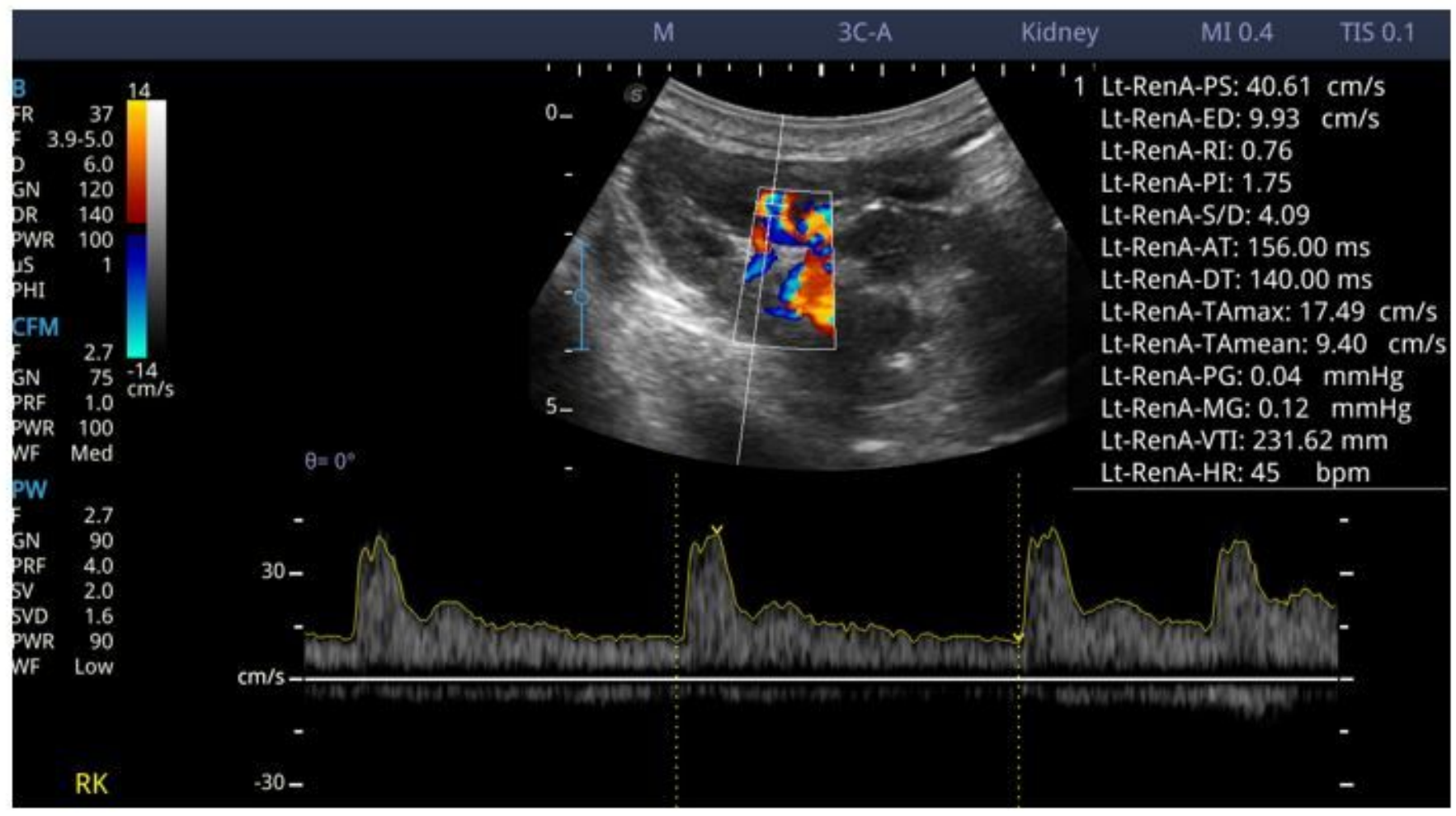

\section{Figure 9}

Pulsed wave Doppler ultrasonographic image of the interlobar artery on 10th day of induction of acute kidney injury showing RI equal 0.76 